\title{
The importance of selecting appropriate compliance and completion criteria during the initial stages of tailings storage facility design
}

\author{
P.J. Chapman Golder Associates Pty Ltd, Australia \\ D.A. Williams Golder Associates Pty Ltd, Australia
}

\begin{abstract}
The potential for environmental impacts and long-term legacies of mining is well documented. However, there appears to be resistance by many industry figures, including mining companies, consultants and regulators, to develop appropriate compliance and completion criteria during the design stage, with the objective of reaching an appropriately and optimally designed facility that is economically, environmental and technically feasible. This paper presents an approach to developing compliance and completion criteria that will facilitate the identification of appropriate design objectives. The objectives can be based on an agreed final landform, mining company standards and long-term legacy to the community. Examples are presented in which air, water and ground issues are explored, including seepage into fresh groundwater and hypersaline groundwater, erosion and water management, as well as dust. As part of each worked example, potential outcomes are presented based on a range of different compliance criteria. This paper also presents a tool that can be used to identify the preferred tailings management solution, based on the identified and agreed compliance and completion criteria.
\end{abstract}

\section{Introduction}

The potential for environmental impacts and long-term legacies of mining is well documented in today's industry (Gray, 1997; Chadwick et al., 1986; Lottermoser, 2007). However, there appears to be resistance by many industry figures, including mining companies, consultants and regulators, to develop appropriate compliance and completion criteria during the design stage, with the objective of reaching an appropriately and optimally designed facility that is economically, environmental and technically feasible.

It is commonplace for tailings storage facility (TSF) designers to adopt operational criteria relating to the structures that are designed. The operational life of a TSF is a small percentage of its total life. The structure is typically built over a period of ten to thirty years, but is required to remain in place thereafter in perpetuity. Despite this, criteria associated with environmental performance are frequently overlooked during the design phase. For example, when considering the stability of an embankment slope during the design stage, designers often reference the Australian National Committee on Large Dams (ANCOLD, 1998, 1999) or the International Committee on Large Dams (ICOLD) for reliability guidelines relating to the acceptable longterm factor of safety, operational factor of safety and factor of safety under seismic conditions. Many papers have been published relating to selection of appropriate seismic coefficients for these analyses (e.g. Bray and Travasarou, 2009) and reducing the selected coefficient to account for the short time-frame in which the seismic event occurs (e.g. Hynes and Franklin, 1984; Kramer, 1996). However, guidelines related to whether on-going seepage through the base of a storage facility is acceptable, or whether erosion of particles from the tailings beach is acceptable are very rare, with good reason - every TSF is set in a unique situation.

The larger mining companies typically have environmental and sustainability policies relating to tailings management. For example, Newmont Asia Pacific's (Newmont's) Environmental Policy (Newmont, 2009) seeks to 'demonstrate leadership in safety, stewardship of the environment and social responsibility'. In regards to Tailings and Water Management, Newmont's policy states that their operations commit to 'design, operate and decommission tailings storage facilities to minimise risks to the environment and stakeholders' and 'minimise depletion and degradation of scarce water resources by maximising water recycling and water efficiency and preventing water pollution'. Similarly, Barrick Gold Corporation (Barrick) states that they currently use 'the Mining Association of Canada's 'A Guide to the Management of Tailings Facilities' to guide the design, operation and closure of our tailings facilities.' (Barrick, 2007) and BHP Billiton 
(BHPB) has its own Health, Safety, Environment and Community Standards that 'require strict controls on tailings management, heap leach residues and waste rock stockpile construction with the aims of minimising the disturbance of land, ensuring their physical stability and managing potential impacts to soil, surface and ground water' (BHPB, 2006).

These companies are considered to be amongst those demonstrating leading practise associated with tailings management. All mining companies should be striving to achieve leading practise by adopting guidelines, such as those adopted by Newmont, Barrick and BHPB, as well as other more region specific guidelines such as those published by the Mining Association of Canada (MAC, 1998) or the Department of Minerals and Energy in Western Australia (DME, 1999) (now regulated by the Department of Mines and Petroleum (DMP)).

However, these guidelines, policies and standards documents are insufficiently specific to allow the designer to address typical questions such as:

- Is some dusting from the tailings beach acceptable? If so, how much?

- Is some erosion of tailings solids or other soils forming the containing embankments acceptable? If so, how much and does it need to be preserved?

- Does the facility need to be lined?

- Is an increase in the groundwater level acceptable?

- What level of air pollution is acceptable?

- What rate of seepage is acceptable?

All of these questions can be addressed through three all encompassing questions:

- What are the environmental compliance criteria that the TSF design needs to satisfy?

- Where will the points of measurement be?

- What is the design life for the finally completed structure?

This paper attempts to assist the designer and owner to answer these questions by presenting an approach to developing appropriate environmental compliance and completion criteria to meet a particular objective. The design objectives can be based on agreed final landform, mining company standards and long-term legacy to the community.

It is acknowledged by the authors that the desired outcomes will vary between facilities, sites, countries and owners. It is with that in mind that the authors recommend using the approach outlined in this paper as early as possible during the design stage, to increase the likelihood of an economically, environmental and technically feasible solution that adheres to the principles of sustainability. This paper also presents a tool that can be used to identify the preferred tailings management solution, based on the compliance and completion criteria developed.

\section{Potential impacts on design and cost}

The importance of establishing agreed compliance criteria at the outset of the design can be demonstrated through examples in which criteria were not established.

\subsection{Case 1 - inappropriate erosion control}

Consider a case in which the designer and owner did not address the potential for erosion of tailings solids from a facility. Many years into operations, the owner observes significant erosion on the downstream slopes, as a result of incident rainfall. The cause of the erosion could be inappropriate design of the stormwater control measures, which allows incident rainfall to accumulate in discreet areas and subsequently flow over the tailings solids, eroding the embankment. While this is considered a minor concern during operations, the long-term implications are significant, and hence the owner will be obliged to armour the 
slopes with competent materials that are more erosion resistant. The surface water drainage features would also need to be addressed, to reduce the likelihood of long-term erosion occurring post-closure.

Both of these remedial actions will be time-consuming and expensive, and could have been avoided through the establishment of erosion criteria during the early stages of design such as:

- Eroded solids from the tailings containment features should not exceed the volume and concentration that can be accommodated by the downstream receiving environment.

- Erosion gullies and drainage features should not exceed the dimensions reflected by natural analogues in the vicinity of the TSF.

These criteria could have been met through installation of sediment traps, coupled with drainage discharge channels at appropriate intervals and grades, complete with appropriately designed filter materials. Incorporating the cost of these items into the operating budget would improve the performance of the facility and reduce the likelihood of extraordinary operating costs and long-term maintenance.

\subsection{Case 2 - inappropriate slope angles}

In typical engineering practice, the design slope for a retaining embankment is a function of the strength of the material (Vick, 1990). In more recent times, the design slope has been modified to take into account other aspects of tailings management, such as progressive rehabilitation or (perceived) erosion control. However, it is only in recent years that the ultimate closure slope is being given the appropriate attention in the design stage.

In most cases, the objective of the closure design is to stabilise the slopes, making them safe, stable and aesthetically acceptable (DME, 1999). One of two directions is usually selected:

- Flattening the slope to less than $20^{\circ}$ to promote vegetation growth.

- Mimicking a natural hill slope by creating a convex-concave slope.

Regardless of which approach is selected, regrading of uniform slopes that are constructed at $2 \mathrm{H}: 1 \mathrm{~V}$ or $3 \mathrm{H}: 1 \mathrm{~V}$ will result in additional costs and time, especially if the operational stage erosion control measures comprised conventional step-ins.

Nevertheless, if the environmental and completion criteria had been established at the outset, it may be possible, for example, to construct relatively steep uniform slopes (say $2 \mathrm{H}: 1 \mathrm{~V}$ ) at the outset of TSF operation and to progressively enhance these slopes into long-term erosion resistant profiles as more waste materials become available during mining operations. This approach would address the DME objectives cited above, as well as similar completion criteria to those in Section 2.1, whilst minimising capital costs.

\subsection{Case 3 - inappropriate selection of compliance point}

The use of liners to inhibit seepage flows from TSFs into the surrounding groundwater is becoming more commonplace in engineering practice. In this case study, consider a situation in which an agreed environmental compliance criterion ahead of design is: no degradation of the existing groundwater quality is to take place, assuming that the groundwater quality is suitable for mining use only. The selection of the compliance point in this case is critical.

If the compliance point selected for the project were directly beneath the liner, the designer would be obliged to install a leachate collection system between two liner systems. This system would collect leakage that may occur through the upper liner and maintain a low hydraulic gradient on the lower liner, thus minimising the seepage reporting to groundwater to a negligible volume.

In contrast to the above, if the compliance point selected is at the lease boundary, the quality of the groundwater could be monitored through the installation of bores and regular sampling, after initially establishing a baseline. This may obviate the need for a complex multiple layer liner system, complete with leachate collection.

In the first case (leachate collection), there would be a significantly higher capital cost and a dramatically reduced risk of seepage causing environmental damage and groundwater degradation. Additionally, the 
design life for the system may stretch beyond the operational life of mine, to account for long-term consolidation and the system may require additional monitoring during both operations and post-closure.

In the second case, the risk of seepage is increased, albeit only slightly, but the capital cost is significantly reduced. In the event that significant amounts of seepage did emerge into the groundwater system, additional costs would be incurred to minimise the environmental impact. Nevertheless, the trade-off between capital cost and risk, in this case, is clear - the only reason a leachate collection system would be installed is if the compliance point selected is to be directly beneath the liner.

\section{Examples of possible criteria based on objective}

The selection of appropriate criteria is inextricably linked to a specific objective or outcome that is sought by the designer, owner or the regulators. More general objectives such as 'minimal erosion of slopes' can result in a wide range of interpretations and could require modifications and remedial measures to be constructed if not specifically addressed during the design phase.

Table 1 presents examples of possible criteria and compliance points associated with slope stability. Reference to a specific outcome or objective to be met is also presented.

Table 1 Possible criteria and compliance points - slope and erosional stability

\begin{tabular}{ll}
\hline Objective or Outcome Desired & Possible Criterion \\
\hline Visual amenity of exposed slopes & Erosion gullies and drainage \\
to be acceptable & features should not exceed the \\
& dimensions reflected by natural \\
& analogues in the vicinity of the \\
& TSF
\end{tabular}

Erosion of solids from exposed slopes to be minimised

Maintain long-term slope stability

Maintain long-term slope stability

Maintain long-term slope stability

Maintain long-term slope stability
Eroded solids from the tailings containment features should not exceed the volume and concentration that can be accommodated by the downstream receiving environment

Sufficient freeboard to contain the probable maximum precipitation event

Factor of safety of greater than 1.5

Probability of slope failure of less than $0.01 \%(1$ in 10,000$)$

No piping erosion to occur through embankment

\section{Possible Compliance Point}

The outer surfaces of the TSF

$10 \mathrm{~m}$ from the toe of the facility

Lowest elevation of the crest of the TSF

Section with maximum height or section with lowest strength parameters

Section with maximum height or section with lowest strength parameters

The outer surfaces of the TSF

The examples provided in Table 1 have been selected to illustrate that there could be multiple criteria and/or compliance points for a particular objective or desired outcome. Using erosional stability as an example, as outlined in section 2.1, the desired outcome or objective can be met in a number of ways, some of which may be unacceptable to the owner or regulators in the short or long term. For example, transport of solids from the slopes may be acceptable, provided they do not impact the downstream embankment, but erosion gullies may not be, due to public perception. Therefore, it would be in the owner's and designer's best interests to agree on the second criterion presented in Table 1. 
Table 2 presents examples of possible criteria and compliance points associated with surface water, seepage and groundwater, with reference to a specific outcome or objectives to be met.

Table 2 Possible criteria and compliance points - seepage and groundwater

\begin{tabular}{lll}
\hline Objective or Outcome Desired & Possible Criterion & Possible Compliance Point \\
\hline $\begin{array}{l}\text { No degradation of surrounding } \\
\text { groundwater }\end{array}$ & $\begin{array}{l}\text { Seepage does not exceed } \\
1,000 \text { litres per day or 0.04\% of } \\
\text { the design contained volume per } \\
\text { day (DME, 2000) }\end{array}$ & Directly beneath the liner \\
$\begin{array}{l}\text { No degradation of surrounding } \\
\text { groundwater }\end{array}$ & $\begin{array}{l}\text { Install natural or synthetic liner } \\
\text { with an equivalent permeability of }\end{array}$ & The liner itself \\
$\begin{array}{l}\text { No0 mm of } 10^{-8} \mathrm{~m} / \mathrm{s} \\
\text { No degradation of surrounding }\end{array}$ & $\begin{array}{l}\text { Groundwater quality to be } \\
\text { returned to baseline levels } \\
\text { following operations }\end{array}$ & $\begin{array}{l}\text { Groundwater quality beneath the } \\
\text { downstream toe of the TSF }\end{array}$ \\
$\begin{array}{l}\text { No degradation of surrounding } \\
\text { groundwater }\end{array}$ & $\begin{array}{l}\text { Groundwater quality to be } \\
\text { maintained downstream of TSF } \\
\text { during operations }\end{array}$ & $\begin{array}{l}\text { Monitoring bores } \sim 100 \mathrm{~m} \\
\text { downstream of TSF }\end{array}$ \\
No detrimental impact on flora & $\begin{array}{l}\text { Maintain groundwater level } 4 \mathrm{~m} \\
\text { below natural ground level during } \\
\text { operations }\end{array}$ & $\begin{array}{l}\text { Beyond cleared areas, i.e. well } \\
\text { outside the footprint of the TSF }\end{array}$ \\
& $\begin{array}{l}\text { Quality of runoff water should not } \\
\text { exceed the volume and } \\
\text { concentration that can be } \\
\text { accommodated by the downstream } \\
\text { receiving environment }\end{array}$ & $\begin{array}{l}\text { Lease boundary or upstream of } \\
\text { critical water supplies }\end{array}$ \\
\hline
\end{tabular}

Consistent with the examples presented in Table 1, the examples in Table 2 illustrate that the specific objectives and outcomes would need to be met by adopting different solutions, depending upon which criterion, or criteria, is/are adopted. The timeframe in which each objective is to be met is also significant, as this could change the required spending pattern and impact the design approach.

For completeness, Table 3 presents examples of possible criteria and compliance points associated with air pollution and dusting, with reference to a specific outcome or objective to be met.

Table 3 Possible criteria and compliance points - air pollution and dusting

\begin{tabular}{|c|c|c|}
\hline Objective or Outcome Desired & Possible Criterion & Possible Compliance Point \\
\hline $\begin{array}{l}\text { No release of asbestiform particles } \\
\text { from tailings beach }\end{array}$ & $\begin{array}{l}\text { Maintain a wet beach prior to } \\
\text { covering with a suitable } \\
\text { containment layer }\end{array}$ & $\begin{array}{l}\text { The air immediately above the } \\
\text { beach }\end{array}$ \\
\hline $\begin{array}{l}\text { Minimise dusting from tailings } \\
\text { beach }\end{array}$ & $\begin{array}{l}\text { Maximum deposited dust level of } \\
4 \mathrm{~g} / \mathrm{m}^{2} / \mathrm{month} \text { (DEC, 2005) }\end{array}$ & The air at the lease boundary \\
\hline $\begin{array}{l}\text { Minimise exhalation of gases from } \\
\text { waste management facility }\end{array}$ & $\begin{array}{l}\text { Minimise volume of gas } \\
\text { exhalation during operations }\end{array}$ & TSF footprint or lease boundary \\
\hline $\begin{array}{l}\text { Minimise exhalation of gases from } \\
\text { waste management facility }\end{array}$ & $\begin{array}{l}\text { Minimise volume of gas } \\
\text { exhalation post-closure }\end{array}$ & $\begin{array}{l}\text { Surface of tailings (above cover) } \\
\text { or downstream of TSF }\end{array}$ \\
\hline
\end{tabular}

It is evident that multiple criteria can be selected to achieve a particular objective, and that interaction between the regulator, the owner and the designer is paramount during the design stage, in order to establish the most appropriate compliance criteria. It is also clear that the designer cannot commence with the design 
until the environmental compliance criteria and their points of measurement are established, as different design solutions will be required for each case.

In addition to the examples provided in Tables 1 to 3 , which contain predominantly operational criteria, the selection of appropriate criteria for closure and completion of the TSF is also important. Closure (the stage immediately following operations in which the owner seeks to create a safe, stable landform) and completion (the stage in which the landform is relinquished to the regulators/government in perpetuity) of a tailings storage facility are becoming increasingly more important in the design stage, as the regulators invariably require at least a conceptual closure plan prior to licensing a facility to operate (DMP, 2007). However, in light of the fact that projects are typically commenced on the basis of the net present value, closure costs are usually very small after discounting, as much of this money is not required to be spent until the end of the project.

Nevertheless, many mining companies are acknowledging that completion of a tailings storage facility is an important part of the mining process, and hence the design of the initial facility is critical. Selection of appropriate completion criteria is therefore required to provide the designer with a closure direction, which may impact the selection of the tailings management approach. For example, as outlined in Section 2.2, if the closure slopes required by the owner were to mimic a natural hill slope by creating a convex-concave slope, the designer could allow for construction of relatively steep uniform slopes (say $2 \mathrm{H}: 1 \mathrm{~V}$ ) at the outset of TSF operation and to progressively enhance these slopes into long-term erosion resistant profiles to meet the completion (relinquishment) criterion, during mining operations.

Table 4 presents examples of possible relinquishment criteria for TSFs, as the objective of TSF completion is to facilitate handover to the government, after the completion criteria have been met.

Table 4 Possible relinquishment criteria and associated closure processes

\begin{tabular}{lll}
\hline Category & Possible Relinquishment Criterion & Closure Process \\
\hline Final land use & $\begin{array}{l}\text { Suitable vegetation that can support light grazing, } \\
\text { consistent with the local area }\end{array}$ & $\begin{array}{l}\text { Construction of suitable } \\
\text { cover and conversion to } \\
\text { grazing land }\end{array}$ \\
Surface treatment & $\begin{array}{l}\text { Demonstrate that stable surface is maintained during } \\
\text { closure process with low likelihood (less than 0.01\%) } \\
\text { of overtopping }\end{array}$ & $\begin{array}{l}\text { Construction of a suitable } \\
\text { cover system to support } \\
\text { vegetation }\end{array}$ \\
Erosional stability & $\begin{array}{l}\text { Eroded solids should not exceed the volume and } \\
\text { concentration that can be accommodated by the }\end{array}$ & $\begin{array}{l}\text { Collect data to support this } \\
\text { criterion }\end{array}$
\end{tabular}

Slope stability $\quad$ Probability of slope failure of less than $0.01 \%$ (1 in 10,000)

Groundwater quality No degradation from pre-mining quality

Groundwater level Levels to be trending towards pre-mining levels with low likelihood (less than $0.01 \%$ ) or reversing the trend, even following large rainfall events

Surface water quality Quality of runoff water should not exceed the volume and concentration that can be accommodated by the downstream receiving environment
Monitor slopes and provide justification to support the slope stability analyses

Capture and treat contaminated seepage or demonstrate that quality is consistent with pre-mining

Lower groundwater levels and collect data to support this criterion

Collect data to support this criterion 


\section{$4 \quad$ Suggested approach to establishing relevant criteria}

Taking cognisance of the examples provided above, it is clear that setting appropriate criteria is not a straightforward process and the standard approach may not always be obvious for the TSF in question. In this section, an approach to establishing relevant criteria is provided, with two examples followed through to provide owners, regulators and designers with an indication of the extent of the process.

As part of the criteria-setting stage (which is encouraged to be carried out early in the TSF design), consideration should be given to including goal-setting approaches commonly used in project management and motivation, namely SMART goals, or Specific, Measurable, Agreed-upon, Relevant and Timely goals (Doran, 1981). This approach has successfully been integrated into many companies' protocols to assist with professional development and provides a focus on the outcomes to be achieved, within a set time period. This is entirely consistent with what is required for TSF design, although 'goals' become 'criteria', as follows:

- Specific: It is clear from sections 2 and 3 that, if the objective or outcome is unclear, the criterion to meet the objective may not be relevant or achievable.

- Measureable: Without a specific value or target, it is difficult to determine when the criterion has been achieved. For example, 'maintaining a stable slope' is not measureable but demonstrating a probability of slope failure of less than $0.01 \%$ is.

- Agreed upon: It is important that the regulators agree on the criteria, with input from the owners and designer, or the individual objectives may be met without satisfying the overall objective of relinquishing the site.

- Relevant: If the criterion (or objective) is irrelevant, valuable resources will be used to meet a criterion that will not assist in relinquishing the site.

- Timely: The objectives and criteria must be related to a specific time (operations, closure, long term, etc.) or the objective could become unclear and irrelevant. For example, maintaining groundwater levels at $4 \mathrm{~m}$ below natural ground level may be appropriate during operations, but may not be for completion. The time that a particular criterion is applicable for therefore needs to be agreed upon.

It should be noted, however, that the site-specific nature of each TSF, combined with the local guidelines and legislation that must be adhered to, as well as the owner's corporate standards, will significantly impact the environmental and completion criteria adopted for the project. The approach presented is therefore a general framework for selection of appropriate environmental compliance and completion criteria. Consideration should also be given to adopting the SMART goal setting approach, in combination with the framework presented.

The recommended approach comprises six simple steps, as follows:

- Step 1 - Identify TSF Location

- Step 2 - Identify Local Legislation and Guidelines

- Step 3 - Identify Criterion Category

- Step 4 - Identify Objective or Outcome

- Step 5 - Identify Compliance Point

- Step 6 - Establish SMART Criterion.

Figure 1 illustrates the recommended approach in a more visual form. Possible questions that should be considered by the owners are included, as well as two worked examples. In terms of consultation (i.e. establishing agreed upon criteria), it is important to confirm the legislative requirements as part of Step 2 and it is strongly recommended that the local regulators are engaged in the process at least as part of Step 4, and preferably as part of Steps 5 and 6. 

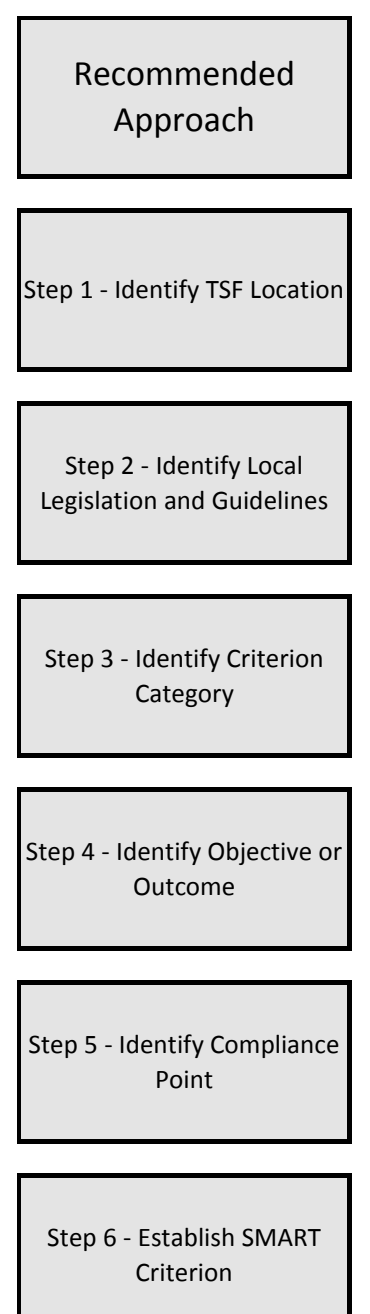

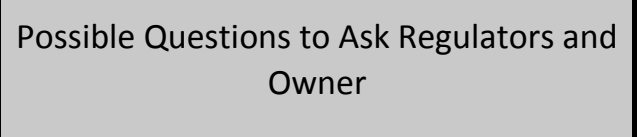

Has a site been selected? What is nearby (villages, railways, etc.)? What is the climatic setting? Has a site investigation been carried out?
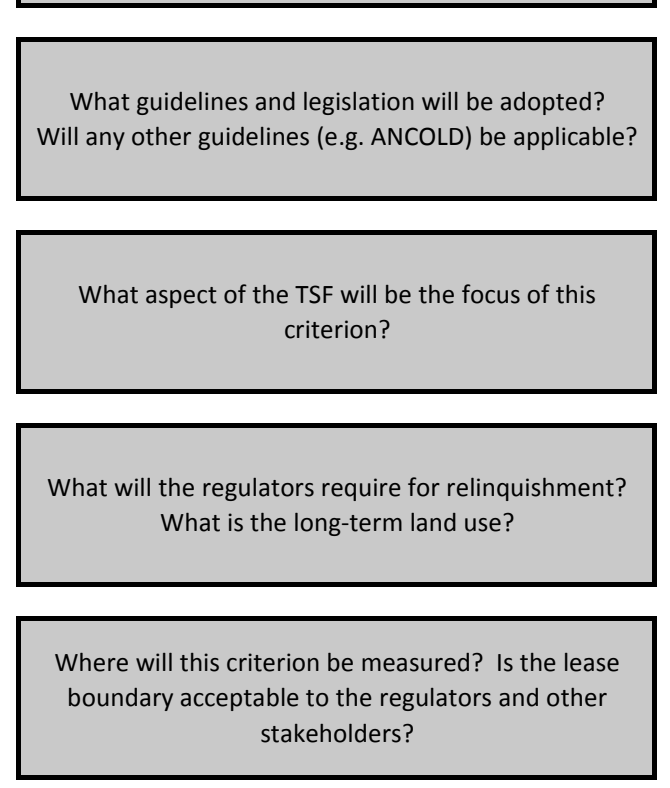

Is there are a risk of fatality if slope failure were to occur? Is overtopping an issue? What will the final slope angles be? Is the groundwater or surface water high quality?

\section{Specific Examples}
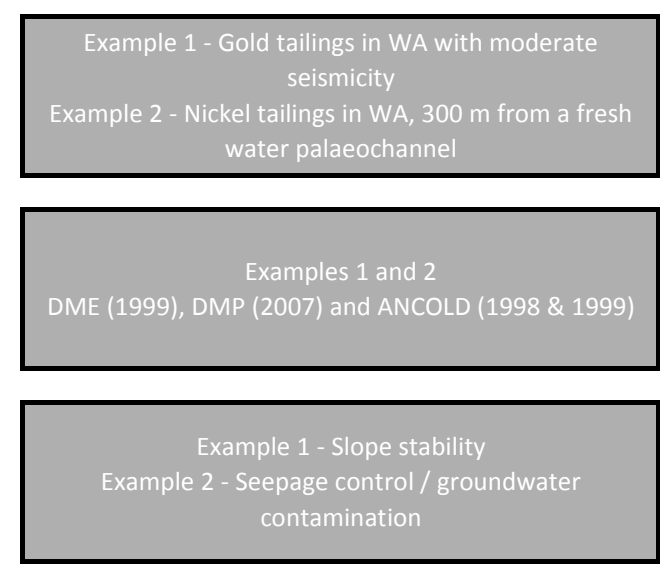

Example 1 - Maintain long-term slope stability Example 2 - No degradation of surrounding groundwate

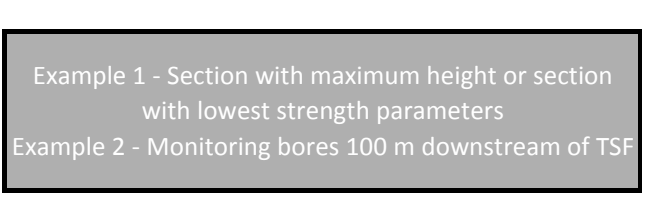

Example 1 - Probability of slope failure $<0.01 \%$ at all times, under both static and seismic conditions xample 2 - Prevent migration of contaminants beyond $100 \mathrm{~m}$ from toe through production bores

\section{Figure 1 Recommended approach for selection of appropriate environmental compliance and completion criteria}

Included in the approach illustrated in Figure 1 are possible questions to ask the owner and, in some cases, the local regulators. The questions provided for Steps 5 and 6 are specific to the examples used to demonstrate the process. However, as outlined in Table 4, there are many other categories that will require criteria to be established. Possible questions related to the other categories are presented here.

\section{Compliance Point Selection}

- Will the compliance point for external impacts be the toe of the facility, directly beneath the facility, at a selected distance (e.g. $100 \mathrm{~m}$ buffer zone) or at the lease boundary?

- Will the compliance point for internal processes (slope stability, erosion) be at the location of occurrence or at the toe of the facility?

\section{Groundwater Impacts}

- Is the groundwater of high quality (e.g. human consumption quality)? What is the recommended use?

- Is the supernatant water contaminated? Is it likely to impact the existing groundwater quality?

- Are minor volumes of seepage acceptable?

- Will an increase in groundwater levels impact local vegetation? 
- Are there any specific guidelines that the owner would like to implement, above and beyond regulatory guidelines?

\section{Erosional Stability}

- Is erosion of the slopes acceptable? If so, to what level?

- Some erosion, but contained within footprint?

- No limit on volume, provided that it does not exceed the volume and concentration that can be accommodated by the downstream receiving environment (i.e. no degradation)?

- Are minor erosion gullies ok? What depth is acceptable?

○ $100 \mathrm{~mm}$ ?

○ $200 \mathrm{~mm}$ ?

- Should not exceed the dimensions reflected by natural analogues in the vicinity of the TSF?

- Should surface water measures be in place to direct stormwater from erodible materials?

\section{Surface and Slope Treatments}

- Is there an advantage in carrying out progressive rehabilitation?

- What will the final slopes look like? Is erosion the key issue?

- Will the community accept rock slopes or is vegetation required?

- Is there topsoil available to assist with revegetation? Is it good quality?

- What are the natural analogues in the area?

- What is the final land use for the area?

The questions presented in this paper are not intended to address every aspect of the TSF, and hence should be used as a guide only. However, the approach presented in this section and illustrated by Figure 1 has been developed to provide a general approach, and can be used to select appropriate compliance points and criteria, provided that a specific objective is identified.

\section{$5 \quad$ Evaluation of options using GoldSET ${ }^{\odot}$}

Using the approach outlined above will result in the establishment of specific design and completion criteria. The designer, in consultation with the owner, will then use these criteria to develop an economically, environmentally and technically acceptable solution for tailings management.

Typically, the approach for selection of an appropriate tailings management solution has focussed on the capital and operating costs for the projects and technical feasibility, with environmental concerns also being included in more recent times, albeit with a low overall weighting. GoldSET ${ }^{\mathcal{O}}$ is a multi-criteria analytical tool that uses indicators (criteria) to evaluate the strengths and weaknesses of engineering projects with respect to the environmental, social, technical and economic dimensions. The tool is an extension of existing practises, with the inclusion of social impacts to the more conventional so-called 'triple-bottom-line' assessment.

GoldSET allows for the comparison of different options on a balanced, impartial, and comprehensive basis. As such, it can help indentify optimal solutions for decision-making based on the principles of sustainable development. The tool was specifically developed to embed sustainable development principles using a number of key indicators and variables into projects, and can summarise interactions of sustainability analyses in easy-to-understand graphical formats.

Figure 2 illustrates the simple process that the user (typically a combination of the owners and the designers in a workshop format) can carry out to assist in identifying the most acceptable solution for tailings management. The selection of indictors is a critical step in the process, and it is recommended that the 
approach outlined in Section 4 be adopted to establish the criteria (indicators) that are relevant to the specific project, and that will provide a meaningful comparison between the tailings management options.

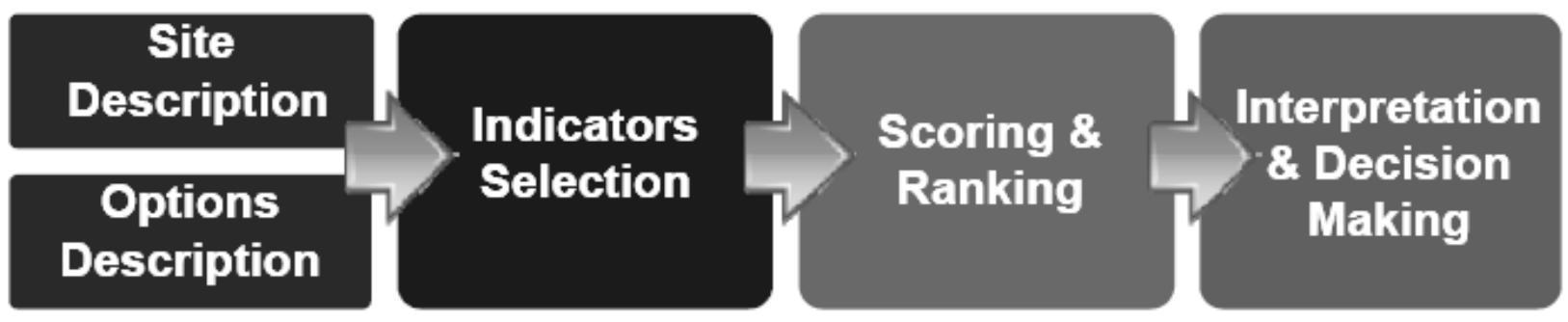

Figure 2 Tailings management selection process

A simple example of the process, taking cognisance of the approach presented in this paper, is the selection of the consistency at which the tailings should be deposited. The options typically considered include:

- Slurry tailings

- Thickened tailings

- Paste tailings

- $\quad$ Filtered (dry stacked) tailings.

If only cost was considered, managing the tailings as slurry would most likely be the selected management technique. When environmental concerns (i.e. supernatant water management and the potential for seepage) are included the selection of the most appropriate management technique is not so straightforward. Moreover, when new technologies are introduced (technical feasibility) and the social setting is considered (community impacts), an unstructured decision-making process is unlikely to be sufficient.

Regulators, especially in the uranium tailings industry (Morrison et al., 2008), are requiring a robust options selection study to be carried out to support the application for a licence to operate. The GoldSET tool provides a structure framework to assist in making the most appropriate design, based on the information available, while also satisfying this requirement.

In the example relating to tailings consistency, the GoldSET tool will assist in incorporating the environmental and social considerations, as illustrated by the following situations:

- If the groundwater system was pristine (human consumption quality water), a filter cake or paste option may be more acceptable socially and environmentally than a synthetic or natural liner and slurry tailings.

- If the supernatant water was able to be recycled efficiently, providing a benefit to local communities, a filter cake or paste option may be more acceptable.

- If a mined out pit void was available and sterilised, in an area of low quality groundwater, depositing the tailings as slurry or as thickened tailings may meet social and environmental criteria, while also being economically and environmentally acceptable to the owner.

Using the GoldSET tool in conjunction with the approach presented in this paper will provide the owner with a robust decision making tool and an economically, environmentally and technically acceptable solution for tailings management.

\section{Conclusions}

It is commonplace for tailings storage facility (TSF) designers to adopt operational criteria relating to the structures that are designed. However, criteria associated with environmental performance are frequently overlooked during the design phase. It is clear by the examples presented that the design should not commence until the environmental compliance criteria and their points of measurement are established, as different design solutions will be required for each case. 
This paper presents an approach to established environmental compliance and completion criteria that adopts the principles of SMART objective setting:

- Specific

- Measureable

- Agreed-upon

- Relevant

- Timely.

The approach provides a general framework for selection of appropriate environmental compliance and completion criteria. It should be noted that the site-specific nature of each TSF, combined with the local guidelines and legislation that must be adhered to and the internal owner standards, will significantly impact the environmental and completion criteria adopted for the project.

The recommended approach comprises six simple steps, as follows:

- $\quad$ Step 1 - Identify TSF Location

- Step 2 - Indentify Local Legislation and Guidelines

- Step 3 - Identify Criterion Category

- Step 4 - Identify Objective or Outcome

- Step 5 - Identify Compliance Point

- Step 6 - Establish SMART Criterion.

Using this approach will result in the establishment of specific design and completion criteria. The designer, in consultation with the owner, will then use these criteria to develop an economically, environmentally and technically acceptable solution for tailings management, provided that the criteria agreed upon during the initial stages of design are not modified during the process. Modification or revision of the criteria may require major redesign and could impact both cost and schedule.

Typically, the approach for selection of an appropriate tailings management solution has focussed on the capital and operating costs for the projects and technical feasibility, with environmental concerns also being included in more recent times, albeit with a low overall weighting. This paper suggests the use of a multicriteria analytical tool (GoldSET) that using indicators (criteria) to evaluate the strengths and weaknesses of candidate tailings management solutions with respect to the environmental, social, technical and economic dimensions. The tool is an extension of existing practises, with the inclusion of social impacts to the more conventional so-called 'triple-bottom-line' assessment.

\section{References}

ANCOLD (1998) Australian National Committee on Large Dams, Guidelines for Design of Dams for Earthquakes, August 1998.

ANCOLD (1999) Australian National Committee on Large, Guidelines on Tailings Dam Design, Construction and Operation, October 1999.

Barrick Gold Corporation (2007) Environmental Policy, http:/www.barrick.com/Corporate Responsibility, accessed 25 May 2010.

BHP Billiton (2006) BHP Billiton Sustainability Report 2006, Environment, Our Approach, Waste Rock and Tailings, http://hsecreport.bhpbilliton.com/2006/environment/ourApproach/wasteRockTailings.asp, accessed 25 May 2010.

Bray, J.D. and Travasarou, T. (2009) Pseudostatic Coefficient for Use in Simplified Seismic Slope Stability Evaluation, Journal of Geotechnical and Geoenvironmental Engineers, Volume 135, Issue 9, pp. 1336-1340.

Chadwick, M.J., Highton, N.H. and Lindman, N. (1986) Environmental impacts of coal mining and utilization, Pergamon Books Inc., Elmsford, NY, 450 p.

Department of Environment and Conservation (DEC) (2005) Approved Methods and Guidance for the Modelling and Assessment of Air Pollutants in NSW. 
Department of Minerals and Energy (DME) (1999) Guidelines on the Safe Design and Operating Standards for Tailings Storage, Department of Minerals and Energy, Western Australia.

Department of Minerals and Energy (DME) (2000) Water Quality Protection Guidelines No. 3, Mining and Mineral Processing, Liners for waste containment, Department of Minerals and Energy, Western Australia.

Department of Mines and Petroleum (DMP) (2007) Mining Proposal in Western Australia, Environmental Division, Minerals Branch, Department of Industry and Resources, Western Australia.

Doran, G.T. (1981) There's a S.M.A.R.T. way to write managements's goals and objectives, Management Review, November 1981, Volume 70, Issue 11.

Gray, N.F. (1997) Environmental impact and remediation of acid mine drainage: a management problem, Environmental Geology, Volume 30, pp. 62-71.

Hynes, M.E. and Franklin, A.G. (1984) Rationalizing the Seismic Coefficient Method, U.S. Department of the Army, Waterways Experiment Station, U.S. Army Corps of Engineers (USACE), Miscellaneous Paper GL 8413.

Kramer, S.L. (1996) Geotechnical Earthquake Engineering, Prentice Hall, Inc., Upper Saddle River, New Jersey, 653 p.

Lottermoser, B.G. (2007) Mine Wastes: characterization, treatment and environmental impacts, 2nd Edition, Spring Berlin Heidelberg, New York, 277 p.

Mining Association of Canada (MAC) (1998) A Guide to the Management of Tailings Facilities, September 1998, http://www.mining.ca/english/publications/tailingsguide.pdf., accessed 25 May 2010.

Morrison, K., Elliot, J., Johnson, J. and Monok, B. (2008) Uranium tailings facility design and permitting in the modern regulatory environment, in Proceedings Tailings and Mine Waste '08, Taylor and Francis Group, London, pp. 205-313.

Newmont Asia Pacific (Newmont) (2009) Environment Policy, http://www.newmont.com/sites/default/files/APACIMS-PL 2002 Environment Endorsed Policy Regional.pdf, accessed 25 May 2010.

Vick, S.G. (1990) Planning, Design, and Analysis of Tailings Dams, John Wiley and Sons. 